\title{
O QUE FAZ O VISITANTE DO INHOTIM TÃO SATISFEITO?
}

\author{
Marlusa de Sevilha Gosling* \\ Danielle Carolina de Queiroz ${ }^{* \star}$ \\ Luciana de Rio Meints*** \\ Juliana Maria Magalhães Christino****
}

\begin{abstract}
O objetivo deste estudo é aprofundar no entendimento dos antecedentes de satisfação de visitantes em museus. Para isso, utilizou-se a teoria do comportamento do consumidor aprofundando em conceitos como a qualidade percebida e a experiência cultural em museus. A variável valor social foi acrescida à escala HISTOQUAL para mensurar aspectos sociais relativos à satisfação. Um questionário presencial foi aplicado com os visitantes do Instituto Inhotim, em Brumadinho (MG). Os autores demonstram que os construtos tangíveis, responsividade, comunicação e valor social explicam cerca de $38 \%$ da satisfação do público. Esta pesquisa contribui para estudos em antecedentes de satisfação de visitantes em museus e com a evolução da HISTOQUAL, escala focada em avaliar a qualidade de lugares históricos, ao aplicá-la em um contexto de brasileiro.
\end{abstract}

Palavras Chave: Museus. Tourismo. Comportamento do consumidor. Satisfação do cliente.

\section{WHAT DOES THE INHOTIM TOURIST SO SATISFAIED?}

The objective of this study is to understand the antecedents of visitor satisfaction in museums. For this, the theory of consumer behavior was used and concepts such as perceived quality and cultural experience in museums. The variable social value was added to the HISTOQUAL scale to measure social aspects related to satisfaction. A face-toface questionnaire was applied with visitors to the Inhotim Institute, in Brumadinho (MG). The authors demonstrate that constructs as tangible, responsiveness, communication and social value explain about $38 \%$ of public satisfaction. This research contributes to studies on the antecedents of visitor satisfaction in museums and to the evolution of HISTOQUAL, a scale focused on evaluating the quality of historical places, when applying it in a Brazilian context.

Keywords: Museum. Tourism. Consumer behavior. Clients' satisfaction.

\section{LO QUE HACE AL VISITANTE DEL MUSEO INHOTIM TAN SATISFECHO ?}

El objetivo de este estudio es profundizar en el entendimiento de los antecedentes de satisfacción de visitantes en museos. Para ello, se utilizó la teoría del comportamiento del consumidor y conceptos como la calidad percibida y la experiencia cultural en museos. La variable valor social se ha incrementado a escala HISTOQUAL para medir los aspectos sociales relativos a la satisfacción. Una entrevista presencial fue aplicado con los visitantes del Instituto Inhotim, en Brumadinho (MG). Los autores demuestran que los constructos tangible, responsividad, comunicación y valor social explican cerca del $38 \%$ de la satisfacción del público. Esta investigación contribuye a estudios en antecedentes de satisfacción de visitantes en museos y con la evolución de HISTOQUAL, escala que evalua la calidad de lugares históricos, al aplicarla en un contexto brasileño.

Palabras Clave: Museo. Turismo. Comportamiento del consumidor. Satisfación del cliente.

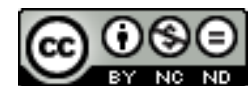

Licenciada por Creative Commons Atribuição Não Comercial / Sem Derivações/ 4.0 / Internacional

\footnotetext{
* Pós-doutora em Gestão do Turismo na Universidade de Algarve (2015). Doutora pela Universidade Federal de Minas Gerais/UFMG (2004). Mestre e Administração pela UFMG (2001). Graduada em Ciência da Computação/UFMG (1992). Atualmente é professora Associada de Marketing da Universidade Federal de Minas Gerais, Coordenadora do NEECIMTUR (Núcleo de Estudos e Estratégias em Comunicação Integrada de Marketing e Turismo) e Coordenadora da PósGraduação Lato Sensu do CEPEAD/FACE/UFMG, curso de Gestão Estratégia. Av. Antonio Carlos, 6627 - Prédio da FACE - Campus UFMG. Belo Horizonte/MG. CEP:31270-901. [ marlusa@ufmg.br]

**Mestranda em Administração pela Universidade Federal de Minas Gerais (2016-2018). Graduação em Comunicação Social pela Pontifícia Universidade Católica de Minas Gerais (2006-2010). É pesquisadora do Núcleo de Estudos e Estratégias de Comunicação Integrada de Marketing e Turismo - UFMG. [ danielle.cqueiroz@gmail.com ]

***Mestranda em Administração pela Universidade Federal de Minas Gerais (2016-2018). Graduação em Administração pela Universidade Federal de Minas Gerais. É pesquisadora do Núcleo de Finanças/UFMG. [ldrmeints@ufmg.br ]

${ }^{* * * *}$ Doutorado em Administração pela Universidade Federal de Minas Gerais/UFMG (2008). Mestre em Administração pela FEAD (2004). Bacharel em administração pela Pontifícia Universidade Católica/PUC (1999). Atualmente é professora do Curso de Administração da Universidade Federal de Minas Gerais/UFMG. [ julianammc@face.ufmg.br ]
} 


\section{INTRODUÇÃO}

Museus têm um papel importante para preservar patrimônios tangíveis e intangiveis de um povo ou lugar. Segundo o Cadastro Nacional de Museus de 2010, no Brasil existem mais de 3 mil museus mapeados sendo que apenas metade deles são cadastrados no órgão. Minas Gerais possui $10 \%$ das instituições culturais do país com mais de 300 estabelecimentos.

Com o foco em aumentar a renda, muitos gestores de instituições culturais têm trabalhado no desenvolvimento de estratégias e ações de marketing (LAMBERT; BOUKAS; YERALI, 2014; BOORSMA; 2006). Museus passaram a se posicionar na internet, com a gestão de websites e a presença em redes sociais para ampliar suas ações de marketing. Belk (2014) reforça a importância das novas mídias como ferramenta de representação neste mundo conectado por redes on-line.

No Brasil, com a crise econômica presente desde o fim de 2014, as instituições culturais veem suas atividades serem prejudicadas devido a queda de investimentos privados e públicos e a diminuição do público. A sustentabilidade financeira de um museu está ligada a políticas públicas, financiamento externos, patrocínios e também a visitação e o retorno de visitantes.

Diversas pesquisas trazem a satisfação como um dos construtos que antecedem a intenção de retorno, lealdade e intenções comportamentais (HOSANY, PRAYAG; ODEH, 2013; ALI, RYU; HUSSAIN, 2015; CHEN, DWYER; FIRTH, 2014). Para relacionamentos de longo prazo e a realização de novos negócios, a satisfação é necessária (LEE et al., 2008). Portanto, preocupar-se com o contentamento do visitante é aspecto essencial para garantir seu retorno.

A questão norteadora desta pesquisa é: o que faz 0 visitante de um museu satisfeito. Sendo assim, o objetivo é entender os antecedentes de satisfação dos visitantes do Instituto Inhotim. Para isso, será utilizada a escala HISTOQUAL (FROCHT; HUGHES, 2000) que tem por objetivo avaliar a qualidade de locais históricos, acrescidas do valor social (WILLIAM; SOUTAR, 2009).

Para entender a satisfação do visitante faz-se necessário aprofundar no estudo da teoria do comportamento do consumidor. São inúmeros os fatores e modelos que estudam os determinantes da conduta de clientes. Estudos recentes como de Berman e Small (2014), Becker-Olsen, Cudmore e Hill (2006) e Straughan e Roberts (2006) trazem panoramas que ampliam o conhecimento sobre a teoria. Mowen (1988) divide o campo nas perspectivas decisória, experiencial e comportamental.
Ao incluir o construto valor social, o presente artigo trata do que Jafari et al. (2013) argumentam em relação questão da sociabilidade na visitação a museu. Nota-se mensurar a influência dessa variável na satisfação de visitantes no contexto de museus no Brasil é algo inovador e abre caminho para agregar as ideias de Jafari et al. (2013) aos modelos de qualidade e satisfação em museus.

Com base nesses conceitos, um survey foi aplicado presencialmente com 230 visitantes do Instituto Inhotim, Centro de Arte Contemporânea e Jardim Botânico, em Brumadinho (MG). 0 método quantitativo permitiu a identificação dos construtos que impactam a satisfação do consumidor, um dos objetivos focais deste estudo. Para avaliação do espaço, a HISTOQUAL (FROCHOT; HUGHES, 2000), escala adaptada da SERVQUAL (PARASURAMAN et al., 1985), foi utilizada como instrumento de pesquisa mensurando dimensões como atendimento, comunicação, aspectos tangíveis da estrutura, consumíveis e empatia da equipe. Os dados foram analisados por meio da análise estatística descritiva e fatorial exploratória.

Os resultados da estatística descritiva mostram uma média alta na avaliação do museu, revelando uma alta satisfação dos visitantes. As dimensões tangibilidade, responsividade, comunicação e valor social juntas explicam $38 \%$ da satisfação dos visitantes. Tais achados contribuem para os gestores de instituições culturais na avaliação dos seus serviços e posterior replanejamento do negócio. 0 artigo contribui com o desenvolvimento da HISTOQUAL ao aplicar a escala em contextos brasileiros e em uma instituição cultural com um perfil que extrapola os limites de um museu.

Para contextualizar o objeto desta pesquisa, 0 Instituto Inhotim é um Centro de Arte Contemporânea e Jardim Botânico localizado há $60 \mathrm{~km}$ de Belo Horizonte, na cidade de Brumadinho (MG). São 140ha de visitação, com 23 galerias com obras de mais de 100 artistas brasileiros e estrangeiros. 0 acervo do Instituto possui 1.300 obras e cerca de 560 estão em exposição. Em termos de Botânica, os jardins do Inhotim possuem aproximadamente cinco mil espécies. No ano de 2015, o Inhotim comemorou o marco de 2 milhões de visitantes e em 2016 dez anos de existência.

Este artigo é estruturado inicialmente com a abordagem da teoria do comportamento do consumidor, passando por conceitos de experiência cultural em museus, qualidade percebida com a apresentação das escalas SERVQUAL e HISTOQUAL e 0 construto valor social. Por último, 0 artigo traz 0 detalhamento metodológico, análise de resultados e conclusão. 


\section{REVISÃO TEÓRICA}

\subsection{Comportamento do consumidor}

O estudo do comportamento do consumidor é uma linha ampla e rica, pois abrange vários aspectos complexos que regem a tomada de decisão de compra e consumo de produtos e serviços, sendo que este processo tem diferentes características quando se trata de diferentes indivíduos.

Mowen (1988) entende que o comportamento de consumo pode ser entendido por três perspectivas: a perspectiva da decisão - que teria como principal objetivo a resolução de problemas -, da experiência que foca não na resolução de problemas, mas na criação de sentimentos e emoções - e do comportamento - na qual os indivíduos agiriam como resposta às pressões do ambiente externo.

Levando em conta a multiplicidade de fatores considerados para identificar os determinantes do comportamento do consumidor, existem vários modelos criados para tentar explicar este fenômeno, cada um considerando características e aspectos diferentes, de acordo com a época de sua proposição.

Novos modelos surgem juntamente com as mudanças no modo de vida e interações das pessoas. Lopes e Silva (2011) apresentam alguns dos modelos vigentes e apontam para a tendência do surgimento de novos modelos comportamentais com base no crescente uso da tecnologia para relacionamento e troca de experiências pelos consumidores, além do interesse por características de produtos e serviços que reflitam seus valores, como preservação ambiental.

De acordo com Pinto e Lara (2008) o campo de pesquisa de comportamento do consumidor, dada sua complexidade, tem também recebido a contribuição de outras áreas do conhecimento, tais como a Antropologia, História, Sociologia e Estatística. Além disso, estes autores enfatizam a dificuldade de pesquisa na área e a necessidade das interações entre disciplinas, uma vez que metodologias tradicionais não são capazes de explicar muitos dos fenômenos que ocorrem no campo do consumo (PINTO; LARA, 2008).

Tendo em vista a ampla gama de aspectos e as constantes mudanças que afetam o comportamento de consumo, vários estudos procuram esclarecer 0 papel de diferentes fatores na decisão de consumir ou não um produto ou serviço.

Como exemplo pode-se citar estudos sobre julgamentos morais (BERMAN; SMALL, 2014), responsabilidade social (BECKER-OLSEN; CUDMORE; HILL, 2006), responsabilidade ambiental (STRAUGHAN; ROBERTS, 2006) e diferenças culturais (DE MOOIJ; HOFSTEDE, 2002) no comportamento dos consumidores.

O comportamento dos visitantes de museus, assim como 0 de quaisquer outros consumidores de produtos ou serviços, também tem múltiplas facetas, fazendo com que a decisão de visitação dependa da consideração de vários aspectos, que são diferentes entre os indivíduos. Assim sendo, a identificação e avaliação da importância de cada um dos fatores são essenciais para melhorar a experiência dos visitantes e, consequentemente, sua satisfação.

\subsection{Consumo em equipamentos turísticos}

O turismo é a atividade econômica que cresce de forma mais rápida no mundo (COSTA et. al., 2017). Revisões bibliográficas sobre 0 comportamento no turismo de uma forma geral são raras provavelmente pela amplitude do campo e conceitos que nem sempre podem ser analisados de forma separada (COHEN; PRAYAG; MOITAL, 2014). McKercher, Denizci-Guillet e Ng (2012) questionam 0 fato de várias teorias e modelos de outras disciplinas serem aplicadas ao turismo. Para os pesquisadores, essa é uma das questões que impedem a inovação na área.

Cohen, Praga e Moital (2014) realizaram uma revisão nas três principais revistas de Turismo Annals of Tourism Research, Tourism Management e Journal of Travel Research - de 2000 a 2012 e descobriram caminhos para pesquisas nos construtos tomada de decisão, valores, motivações, autoconceito e personalidade, expectativas, atitudes, percepções, satisfação, confiança e lealdade. Em relação a satisfação, conceito foco desta pesquisa, os autores identificaram a necessidade em estudos que abordam a heurística da equidade social, a atribuição no contexto turístico, as interações turismo-turistas, aprofundando em conceitos como apego e dependência do local e envolvimento pessoal.

A estrutura do turismo é composta por diferentes elementos, a infraestrutura de acesso (estradas, aeroportos, portos e rodoviárias) em conjunto com a infraestrutura básica (esgoto e iluminação), equipamentos turísticos e equipamentos de apoio (BARRETO, 2006). Para a autora, os equipamentos são aqueles que permitem que serviços turísticos sejam prestados. Por meio destes serviços, o turismo pode possibilitar o exercício da cidadania, como no turismo cultural, que leva a comunidades manifestações artísticas e culturais que muitas vezes estão fora do alcance desses locais.

Neste sentido, este estudo propõe um entendimento do comportamento do consumidor no equipamento turístico Instituto Inhotim. 


\subsection{Experiência cultural em museus}

0 consumo de arte tem importante influência na formação dos indivíduos e na forma como cada um lida com suas questões pessoais. A aquisição e manutenção de capital cultural é uma questão determinante para a relação dos indivíduos com quaisquer formas de arte e manifestações culturais em geral, moldando, assim, a experiência de cada um. 0 capital cultural é tido como algo transmitido no contexto familiar, sendo ele o responsável pela criação de consumidores de cultura. Entretanto, conforme estudo de Kisida et al. (2014), este atributo também pode ser transmitido de outra forma. Os autores constataram que a exposição de alunos a uma instituição cultural foi capaz de despertar o interesse no consumo de cultura e a aquisição de mais capital cultural, principalmente em alunos vindos de classes sociais menos favorecidas (KISIDA et al., 2014).

Além de ser determinada pelo capital cultural dos consumidores, a experiência cultural também está ligada às questões pessoais de cada um. Os benefícios e possíveis malefícios do contato com a arte foram delineados em estudo de Foreman-Wernet e Dervin (2011), no qual os autores demonstraram o impacto do contato com a arte em indivíduos que lidavam com diferentes contextos tidos como menos favoráveis, como questões relacionadas à orientação sexual, divórcio, raça, classe social e noção de gênero. Com base nos resultados obtidos, foi possível perceber como as experiências culturais são formadas e desenvolvidas de acordo com estas condições (FOREMAN-WERNET; DERVIN, 2011).

Especificamente no contexto dos museus, a visão sobre o conceito de experiência tende à consideração de aspectos físicos do local (JAFARI et al., 2013). As instalações são, portanto, críticas para o sucesso e popularidade destas instituições. De acordo com Kovach (2014), a existência de lojas nas dependências dos museus contribuiu para o desenvolvimento da experiência dos visitantes, com base em sua busca por novidades e nostalgia. As lojas de museus se tornaram um local para a aquisição de mercadoria de luxo, mas também para que 0 consumidor pudesse apoiar uma causa, no caso, o próprio museu (KOVACH, 2014).

Além do aspecto puramente do consumo, Jafari et al. (2013) destacam o aspecto social dos museus: os visitantes socializam dentro e fora deles, dividindo os significados atribuídos à arte neles presente, bem como seus sentimentos com relação a ela. Estes autores entendem que a experiência nos museus não deve somente ser interpretada como uma experiência de consumo em si, mas também como uma experiência social, na qual os indivíduos constroem impressões não só sobre os objetos, mas também sobre si mesmos e sobre os outros à sua volta (JAFARI et al., 2013). Estes autores argumentam que a consideração deste potencial é capaz de aumentar 0 valor destas construções na sociedade em constante mudança. Portanto, pode-se perceber que os museus não estão apenas ligados ao que ver e com o que se relacionar; eles também estão ligados a quem ver e com quem se relacionar (JAFARI et al., 2013, p. 1746).

\subsection{Qualidade percebida}

A qualidade dos serviços prestados ao consumidor tem ganhado atenção crescente e tem sido 0 foco das empresas e instituições que procuram se destacar e ter sucesso no mercado. Seth, Deshmukh e Vrat (2005) ressaltam que aspectos como a globalização, internacionalização dos serviços e uso cada vez maior de ferramentas de tecnologia para disseminar informações, aliados a consumidores exigentes e sempre conectados, contribuíram para alterar o foco das empresas da simples maximização dos lucros para maximização de lucros por meio do aumento da satisfação do cliente.

Assim, a maior ênfase deve ser dada ao desempenho percebido pelo consumidor, uma vez que o que impacta na satisfação é a qualidade percebida (LEE; LEE; YOO, 2000). Com base nestas condições, o que deve ser avaliado não são apenas os processos em si, mas também como eles são entregues (SETH; DESHMUKH; VRAT, 2005), de modo que a qualidade percebida do serviço seja alta e faça diferença na escolha futura dos usuários dos serviços.

Com o objetivo de lidar com estas questões e obter vantagem competitiva no fornecimento de produtos e serviços, quaisquer que sejam eles, as organizações colocam em prática algumas ferramentas para a avaliação da qualidade percebida pelos clientes, de modo a verificar a eficácia de suas iniciativas presentes e identificar possibilidades de melhoria para aumentar a satisfação. Para o caso dos serviços, uma das medidas que pode ser utilizada é a escala SERVQUAL, desenvolvida por Parasuraman et al. (1985), para lidar com uma falta de pesquisas sobre a qualidade de serviços na época, uma vez que este aspecto relativo aos produtos tangíveis já havia sido estudado e mensurado de maneira significativa, mas a mesma abordagem não existia para serviços. A escala HISTOQUAL (FROCHOT; HUGHES, 2000) é uma adaptação da escala SERVQUAL para locais históricos, que permite a identificação de forças e fraquezas na prestação de serviços nestes espaços.

Para a realização do presente estudo, serão utilizadas estas escalas como forma de mensurar a qualidade percebida, e, consequentemente, a satisfação dos visitantes de museus em Belo Horizonte. 


\subsubsection{Escala SERVQUAL}

O estudo que deu origem à escala SERVQUAL data de 1985, e se justifica pela carência de pesquisas que exploram a qualidade de serviços, ao passo que pesquisas sobre a qualidade de produtos eram mais numerosas. Esta diferença deve-se pela maior facilidade de avaliar qualidade de produtos devido a sua tangibilidade, o que está ausente no caso de serviços (PARASURAMAN et al., 1985).

Por meio de entrevistas com gestores de empresas prestadoras de serviços e consumidores, os autores foram capazes de identificar dimensões utilizadas para a criação de expectativas sobre os serviços e a percepção de sua qualidade, bem como enumerar algumas lacunas existentes entre as percepções dos gestores e dos clientes, que poderiam afetar a qualidade percebida pelos clientes (PARASURAMAN et al., 1985). A figura 1 mostra, de forma esquemática, a relação entre os fatores determinantes da qualidade de serviços e as lacunas que podem existir, sob as visões do consumidor e do prestador.

Figura 1: Modelo de Lacunas.

Consumidor

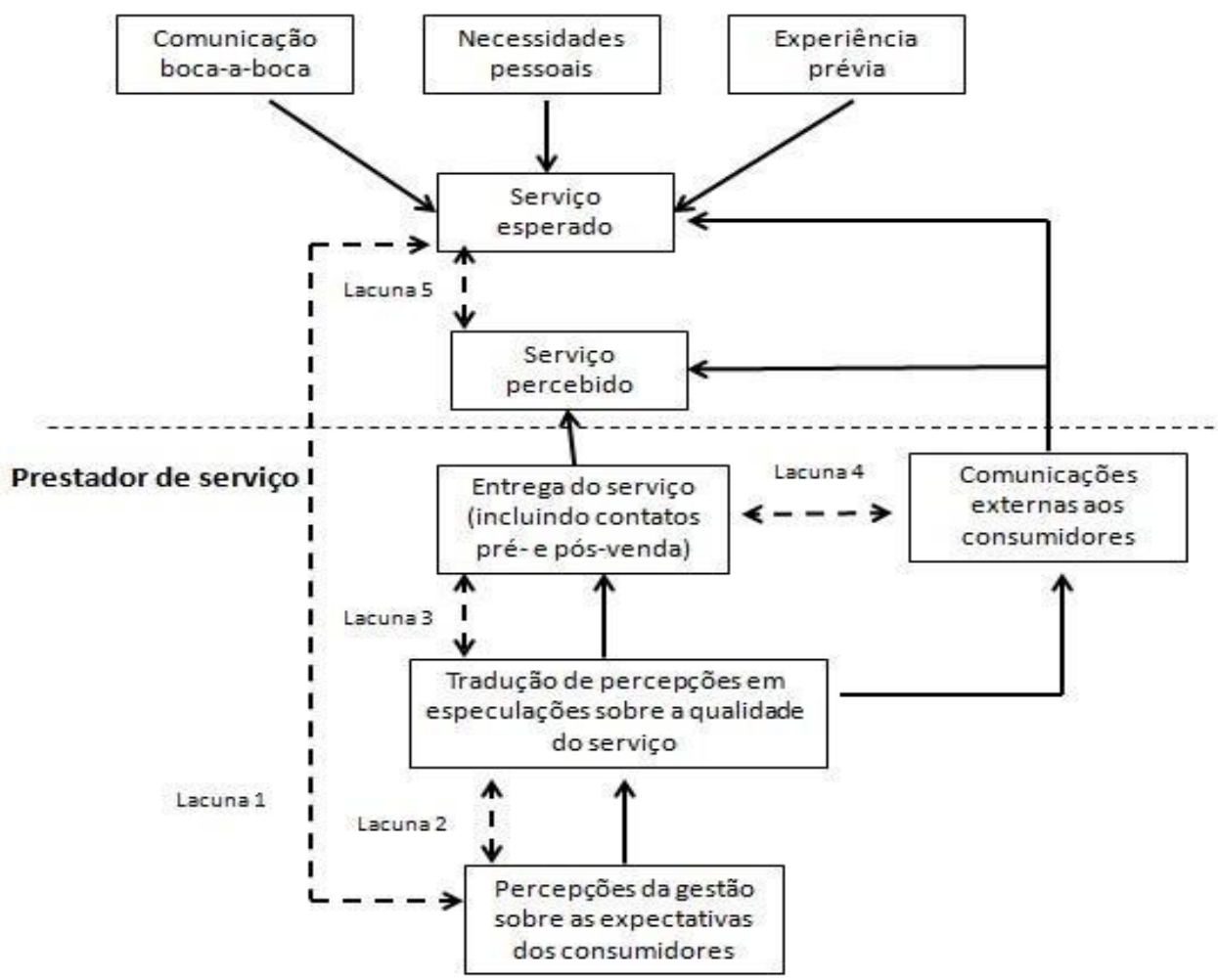

Fonte: Parasuraman et al., 1985 (adaptado).

Além de avaliar estes fatores, são também apontados os fatores determinantes da qualidade percebida do serviço, a qual resulta da comparação entre o serviço esperado e o percebido pelo cliente (PARASURAMAN et al., 1985). Os autores salientam que esta comparação não é diferente daquela feita quando produtos são avaliados. A diferença no caso dos serviços é a natureza das características com que eles são avaliados (PARASURAMAN et al., 1985, p. 47-48). Na figura 2 é possível observar como os fatores determinantes da qualidade interagem para formar as expectativas e determinar a percepção de qualidade.

A escala foi desenhada para aplicação em uma ampla gama de serviços, e possui bom grau de validade e confiabilidade (PARASURAMAN et al.,
1988; 1991). É baseada em cinco dimensões da prestação de serviços, a saber: tangíveis (instalações, equipamentos, aparência dos empregados), confiabilidade (habilidade de desempenhar o serviço esperado de maneira precisa e confiável), capacidade de resposta (disposição para ajudar e fornecer serviço rápido), garantia (conhecimento e cortesia dos empregados e sua capacidade de passar confiança) e empatia (atenção cuidadosa e individualizada oferecida aos clientes). Sua aplicação e revisão reiteram estes aspectos e fornecem orientações para seu uso mais eficiente, uma vez que a escala serve como como um ponto de partida útil, não a resposta final para a avaliação de melhora da qualidade de serviços (PARASURAMAN et al., 1991, p.445). 
Figura 2: Qualidade em Serviços.

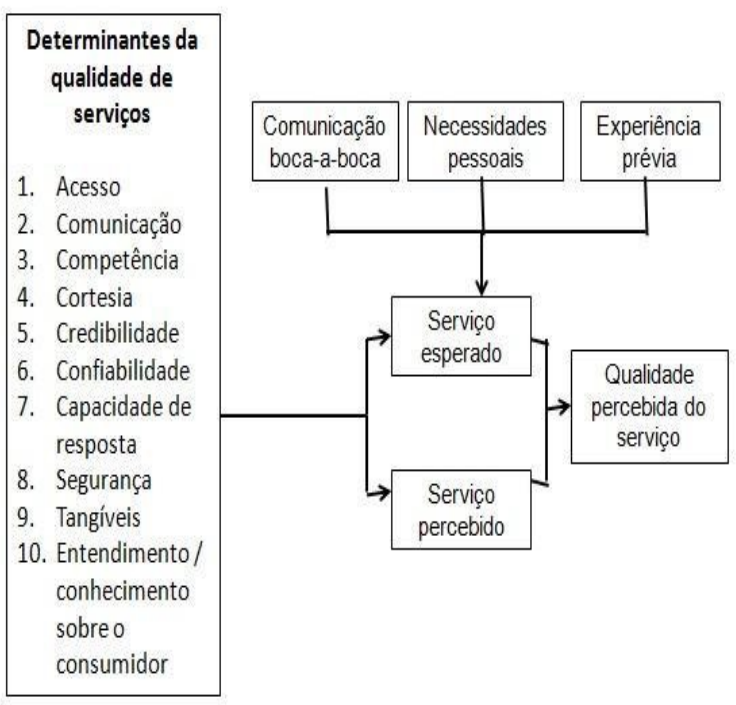

Fonte: PARASURAMAN et al., 1985 (adaptado).

Entretanto, o desenvolvimento de uma escala abrangente como a SERVQUAL também gera controvérsias sobre sua aplicabilidade e confiabilidade. Babakus e Boller (1992) afirmam que 0 desenvolvimento de uma ferramenta que seja aplicável a uma grande variedade de serviços pode não ser eficiente, uma vez que a complexidade do conceito de qualidade do serviço pode variar de setor para setor. Assim sendo, uma medida específica para cada indústria de serviços pode ser uma estratégia mais viável. Brown, Churchill e Peter (1993) apresentam uma crítica à ferramenta relativa à operacionalização do construto qualidade de serviços, para os quais os idealizadores da escala apresentaram contraargumentos para a explicação da validade da escala (PARASURAMAN et al., 1993).

Embora possa apresentar algumas lacunas e limitações à sua utilização em determinados setores, a escala SERVQUAL tem utilizações em pesquisas, passadas e mais recentes, sobre a percepção da qualidade de serviços pelos consumidores. Estudos documentados apresentam a sua aplicação em uma variedade de contextos de avaliação de diferentes serviços, como restaurantes (LEE; HING, 1995), hotéis (SALEH; RYAN, 1991), bancos (NEWMAN, 2001), serviços públicos (WISNIEWSKI, 2001), web sites (VAN IWAARDEN et al., 2003) e educação (TAN; KEK, 2004).

\subsubsection{Escala HISTOQUAL}

A escala HISTOQUAL (FROCHOT; HUGHES, 2000), utilizada para avaliar serviços de locais históricos, foi desenvolvida para lidar com a limitação da escala SERVQUAL em abranger todos os tipos de serviços. Uma escala mais específica teria maior capacidade de avaliar os serviços de certas organizações, inclusive de museus e demais atrações históricas. Frochot e Hughes (2000, p.166) argumentam que, embora a escala SERVQUAL seja uma ferramenta muito útil, ela deve ser adaptada quando se considera novos serviços, e particularmente serviços relacionados a patrimônios históricos.

O desenvolvimento desta escala ocorreu de forma similar à documentada por Parasuraman et al. (1985) para a formulação da escala SERVQUAL. A escala HISTOQUAL se baseia nas mesmas dimensões, porém se mostra mais vantajosa no sentido de equilibrar os resultados com a importância dada às diferentes dimensões pelos visitantes de museus, mostrando que os aspectos tangiveis e de comunicação se destacam no fornecimento de serviços em construções culturais (FROCHOT; HUGHES, 2000).

Deste modo, a utilização da escala HISTOQUAL (ver se justifica devido às diferenças entre os serviços considerados convencionais e o serviço prestado aos visitantes de museus, dada a diferente natureza destes dois serviços, o que impacta nas expectativas e, consequentemente, na qualidade percebida pelos clientes.

Tabela 1 - Escala HISTOQUAL.

\begin{tabular}{l|l|l}
\multicolumn{2}{c|}{ Dimensão } & \multicolumn{2}{c}{ Itens } & \\
\hline \multirow{2}{*}{ Atendimento } & A equipe é sempre atenciosa e cortês. & \\
\cline { 2 - 3 } & Os funcionários estão dispostos a atender os visitantes & \multirow{2}{*}{$\begin{array}{l}\text { Frochot e Hughes } \\
(2000)\end{array}$} \\
\cline { 2 - 3 } & Os visitantes se sentem bem-vindos & \\
\cline { 2 - 3 } & O nível de aglomeração é tolerável. & \\
\cline { 2 - 3 } & Os funcionários são bem informados para responder às solicitações dos clientes. & \\
\cline { 2 - 3 } & Os visitantes se sentem livres para explorar e não há restrições ao acesso. & \\
\hline
\end{tabular}




\begin{tabular}{|c|c|c|}
\hline & A propriedade e os jardins são abertos em horários convenientes. & \\
\hline & Os funcionários estão sempre disponíveis quando necessário. & \\
\hline \multirow{7}{*}{ Tangiveis } & A propriedade está bem conservada e restaurada. & \multirow{7}{*}{$\begin{array}{l}\text { Frochot e Hughes } \\
(2000)\end{array}$} \\
\hline & A limpeza e manutenção geral da propriedade é satisfatória. & \\
\hline & A propriedade é atraente. & \\
\hline & O local permaneceu autêntico. & \\
\hline & A sinalização na propriedade e jardins é clara e útil. & \\
\hline & O jardim e/ou parque contêm uma grande variedade de plantas. & \\
\hline & O interior da casa oferece várias coisas interessantes para olhar. & \\
\hline \multirow{4}{*}{ Comunicação } & Os folhetos escritos fornecem informações suficientes. & \multirow{4}{*}{$\begin{array}{l}\text { Frochot e Hughes } \\
(2000)\end{array}$} \\
\hline & As informações sobre a propriedade são detalhadas o suficiente. & \\
\hline & $\begin{array}{l}\text { Os visitantes são bem informados das diferentes instalações e atrações disponiveis } \\
\text { na propriedade. }\end{array}$ & \\
\hline & Folhetos em língua estrangeira são úteis. & \\
\hline \multirow[t]{3}{*}{ Consumíveis } & O restaurante oferece uma grande variedade de pratos e bebidas. & \multirow{3}{*}{$\begin{array}{l}\text { Frochot e Hughes } \\
(2000)\end{array}$} \\
\hline & A loja oferece uma grande variedade de produtos. & \\
\hline & Funcionários do restaurante prestam serviço eficiente. & \\
\hline \multirow[t]{2}{*}{ Empatia } & A propriedade considera as necessidades dos visitantes com deficiência. & \multirow{2}{*}{$\begin{array}{l}\text { Frochot e Hughes } \\
(2000)\end{array}$} \\
\hline & Instalações físicas para crianças são oferecidas. & \\
\hline
\end{tabular}

Fonte: Frochot e Hughes (2000).

\subsection{Valor social}

Conforme a observação de que a experiência em museus não se resume à esfera cultural, mas também possui características sociais, pode-se destacar o papel dos museus para a construção de valor social para a sociedade e para seus visitantes. Como a satisfação dos clientes está ligada à experiência global, que inclui lazer, cultura, educação e socialização (CHEN; CHEN, 2010), os museus tendem a incorporar esta tendência, oferecendo possibilidades para que o lado social dos seus visitantes também seja explorado. Isto ocorre, entre outros, por meio do fenômeno denominado social tagging, no qual, por meio da tecnologia, os museus e os usuários podem se relacionar e cultivar este relacionamento (TRANT; WYMAN, 2006).

Os museus e outras construções históricas têm potencial para influenciar a maneira que os indivíduos e as comunidades entendem a si próprias e suas relações com outros (NEWMAN; McLEAN, 2004), sendo, portanto, ferramentas para criação de valor social. $\mathrm{O}$ valor de uma experiência satisfatória em museus vai além daquela ocorrida dentro dele, mas se estende para depois que os indivíduos retornam para suas vidas cotidianas (PACKER, 2008).

Deste modo, a socialização ocorrida nas visitas a museus e também devido a elas pode ser visto como um grande motivador para a continuidade $e$ regularidade das visitas e também para 0 compartilhamento de experiências. De acordo com 0 observado por Scott (2003), o impacto dos museus é significante, sendo direta ou indiretamente responsável pelo aumento de capital humano e social, construção de sentimento de comunidade, mudança na sociedade e desenvolvimento econômico.

O impacto dos museus é, então, de grande valor para os visitantes e para a sociedade em geral. Entender as motivações dos frequentadores destes locais contribui para o entendimento não somente de seus desejos, necessidades e aspirações pessoais, mas também para a compreensão de como os museus e demais atrações culturais contribuem para a formação e desenvolvimento da identidade cultural e social de cada um desses indivíduos.

\subsection{Satisfação}

Considerando que o propósito das instituições é 0 
de satisfazer ao cliente, uma vez que este aspecto é o principal determinante para 0 consumo regular $e$ compartilhamento de experiências, é crucial a definição do que determina a satisfação do consumidor em cada contexto. A percepção do cliente sobre a qualidade do produto ou serviço oferecido é o ponto mais importante na determinação da satisfação, e cabe às empresas e instituições reduzir ao máximo a lacuna entre qualidade esperada e qualidade percebida, de modo a maximizar a satisfação. Este processo requer reavaliação constante das expectativas dos consumidores, para que a empresa possa medir e controlar seu esforço para a satisfação destas expectativas (MARCHETTI; PRADO, 2001). Entretanto, a simples satisfação das necessidades ou desejos dos consumidores não resulta necessariamente na fidelidade destes (RODRIGUES, 2003). Por este motivo, o que deve ser buscado é a fidelização, ao invés de somente satisfação momentânea.

A satisfação alcançada depende da expectativa criada para a experiência. De acordo com De Rojas e Camarero (2008), esta expectativa é determinada por aspectos cognitivos - relativos à qualidade percebida e emocionais - relacionados ao prazer da experiência. A combinação dos dois leva à satisfação, sendo que a qualidade percebida é mais saliente que as emoções na determinação da satisfação. No caso específico dos museus, a experiência total que determina a satisfação engloba uma série de transações individuais, sendo que a experiência total é diferente entre grupos de consumidores (ROWLEY, 1999).

A satisfação do consumidor pode ser entendida, então, como uma combinação das expectativas criadas e da experiência total proporcionada pela atração. Assim sendo, a principal maneira de maximizar a satisfação de modo a considerar a experiência de consumo bem-sucedida depende da observação de características de cada consumidor - ou visitante, no caso de museus e locais afins - para proporcioná-lo não somente uma experiência cultural, mas também de lazer, aprendizado e socialização, que possa ser aproveitada não somente durante sua permanência, mas também levada para fora do local em questão e compartilhada de maneira positiva.

\section{METODOLOGIA}

Esse artigo tem como objetivo identificar os construtos que impactam a satisfação do visitante do Instituto Inhotim, centro de arte contemporânea e jardim botânico localizado em Brumadinho (MG).

É um estudo de abordagem quantitativa com um levantamento de campo que possibilita a verificação e teste do relacionamento entre as variáveis (BABBIE, 2007). $O$ instrumento de coleta foi baseado na escala HISTOQUAL (FROCHT; HUGHES, 2000) que tem por objetivo avaliar a qualidade de locais históricos. Tal escala analisa cinco sub-dimensões: responsividade, tangibilidade, comunicação, consumíveis e empatia. Para mensurar quesitos sociais, foi acrescido à escala HISTOQUAL (FROCHT; HUGHES, 2000) o construto valor social (WILLIAMS; SOUTAR, 2009). O instrumento de pesquisa utiliza a escala Likert com onze pontos entre 0 "discordo totalmente" e 10 "concordo totalmente" e foi aplicado como pré-teste para 12 estudantes de pós-graduação. Após os ajustes necessários apontados no pré-teste, 0 instrumento foi apresentado aos gestores, que aprovaram a versão da tabela 2 para coleta. No total, foram testados 24 itens (tabela 2).

Tabela 2 - Itens escala HISTOQUAL e valor social.

\begin{tabular}{|c|c|c|}
\hline Construtos & Itens & Fonte \\
\hline \multirow{8}{*}{$\begin{array}{l}\text { Responsividade/ } \\
\text { Atendimento }\end{array}$} & RESP1: Funcionários são sempre corteses e & \multirow{8}{*}{$\begin{array}{l}\text { Adaptado de } \\
\text { Frochot e Hughes } \\
(2000)\end{array}$} \\
\hline & RESP2: Os funcionários estão dispostos a atender os visitantes & \\
\hline & RESP3: Os visitantes se sentem bem-vindos & \\
\hline & RESP4: O nível de aqlomeracão é tolerável. & \\
\hline & RESP5: Funcionários são bem informados para & \\
\hline & RESP6: Visitantes se sentem livres para explorar & \\
\hline & RESP7: A propriedade e suas áreas externas & \\
\hline & RESP8: Funcionários estão sempre disponíveis & \\
\hline \multirow{3}{*}{ Tangíveis } & TANG1: A propriedade se mostra em bom estado & \multirow{3}{*}{$\begin{array}{l}\text { Adaptado de } \\
\text { Frochot e Hughes } \\
(2000)\end{array}$} \\
\hline & TANG 2: A limpeza qeral e a manutenção da propriedade e suas áreas externas são & \\
\hline & TANG3: Placas indicam adequadamente locais a & \\
\hline
\end{tabular}




\begin{tabular}{|c|c|c|}
\hline & TANG4: A propriedade oferece várias coisas & \\
\hline \multirow[t]{4}{*}{ Comunicação } & COM 1:Folhetos escritos fornecem informações & \multirow{4}{*}{$\begin{array}{l}\text { Adaptado de } \\
\text { Frochot e Hughes } \\
(2000)\end{array}$} \\
\hline & COM2: A informacão acerca da propriedade e suas áreas externas é detalhada de & \\
\hline & COM3: Visitantes são bem informados sobre & \\
\hline & COM4: Folhetos escritos em línquas estrangeiras & \\
\hline \multirow[t]{3}{*}{ Consumíveis } & CONS1: O restaurante oferece uma grande variedade de comidas e bebidas. & \multirow{3}{*}{$\begin{array}{l}\text { Adaptado de } \\
\text { Frochot e Hughes } \\
(2000)\end{array}$} \\
\hline & CONS2: A loia oferece uma grande variedade de & \\
\hline & CONS3: Funcionários do restaurante oferecem um serviço eficiente. & \\
\hline \multirow[t]{2}{*}{ Empatia } & EMP 1: A propriedade considera as necessidades & \multirow{2}{*}{$\begin{array}{l}\text { Adaptado de } \\
\text { Frochot e Hughes } \\
\text { (2000) }\end{array}$} \\
\hline & EMP 2: Existem instalações voltadas para o público infantil. & \\
\hline \multirow[t]{3}{*}{ Valor social } & VALSOC1: Participar dessa experiência me permitiu criar uma boa impressão & \multirow{3}{*}{$\begin{array}{l}\text { Adaptado de } \\
\text { Williams e Soutar } \\
\text { (2009) }\end{array}$} \\
\hline & VALSOC2: Participar dessa experiência me permitiu impressionar outras pessoas & \\
\hline & VALSOC3: Participar dessa experiência me permitiu me sentir mais socialmente & \\
\hline \multirow[t]{3}{*}{ Satisfação } & SAT1: Estou satisfeito com a minha decisão de & \multirow{3}{*}{$\begin{array}{l}\text { Adaptado de Oliver } \\
\text { (1997) }\end{array}$} \\
\hline & SAT2: Minha decisão de participar dessa experiência foi sábia. & \\
\hline & SAT3: Foi uma boa experiência. & \\
\hline
\end{tabular}

Fonte: elaborado pelos autores (2017).

A coleta aconteceu no dia 26/10, quarta-feira, momento em que o museu é aberto ao público e com um fluxo maior de visitantes. $O$ questionário foi aplicado presencialmente com pesquisadores treinados e em entrevistas de no máximo 10 minutos. A coleta mínima deveria ser de 205 questionários de acordo com as orientações de Hair et. al. (2014). A amostra foi selecionada por conveniência, isto é, os visitantes eram abordados ao final da visita e quem se sentiu à vontade, respondeu. No total, foram 230 respondentes de 4 países, de 8 estados brasileiros e de mais de 40 cidades. Em sua maioria, os visitantes eram de Belo Horizonte (MG).

\section{ANÁLISE E DISCUSSÃO DE RESULTADOS}

Como dito anteriormente, foram coletados 230 questionários, sendo que houve 2 outliers univariados e 4 outliers multivariados. Esses seis casos foram retirados.

A linearidade foi atestada a partir da correlação de Spearman, presente em mais de $90 \%$ das relações entre todas as variáveis.

Não foi possivel atestar a normalidade univariada, a partir do teste Kolmolgorov-Smirnov. Sendo assim, a ausência de normalidade univariada leva à ausência de normalidade multivariada (HAIR et al, 2005). Dessa forma, o modelo foi testado por meio de um software que não pressupõe normalidade dos dados, isto é, o SMartPLS.

\subsection{Estatísticas descritivas}

\subsubsection{Estatísticas descritivas dos construtos}

Primeiramente, este estudo apresenta as estatísticas descritivas dos dados coletados. As médias das respostas foram altas, sendo que a menor média verificada foi referente à variável EMP2, relativa às instalações físicas voltadas ao público infantil. Realmente, existe carência desse tipo de espaço em Inhotim e as famílias, que são um público que visitam bastante o local, ficam às vezes sem opção para os filhos menores. A variável de maior desvio-padrão foi VALSOC3, isto é, associar a experiência da visita com ser socialmente aceito foi a afirmativa com a qual os entrevistados mostraram-se menos coerentes, com um todo, já que houve grande variabilidade de respostas.

Nota-se, também, que em geral as médias das dimensões de qualidade (HISTOQUAL) foram altas, demonstrando que os entrevistados perceberam qualidade nos quesitos. Todos os itens de satisfação tiveram médias acima de 9 , ou seja, os visitantes estão muito satisfeitos com o local. 
Tabela 3 - Estatísticas Descritivas dos Construtos.

\begin{tabular}{|c|c|c|c|c|c|}
\hline & \\
\hline & N (Válido) & Mínimo & Máximo & Média & $\begin{array}{l}\text { Desvio } \\
\text { Padrão }\end{array}$ \\
\hline $\begin{array}{l}\text { RESP1: Funcionários são sempre corteses e dispostos a ajudar no que for } \\
\text { necessário }\end{array}$ & 230 & 5 & 10 & 8,90 & 1,252 \\
\hline RESP2: Funcionários estão dispostos a passar o tempo com os visitantes & 230 & 0 & 10 & 7,17 & 2,243 \\
\hline RESP3: Visitantes se sentem bem vindos & 230 & 3 & 10 & 9,29 & 1,154 \\
\hline RESP4: Nível de lotação de pessoas é tolerável & 230 & 2 & 10 & 8,58 & 1,788 \\
\hline $\begin{array}{l}\text { RESP5: Funcionários são bem informados para responder às dúvidas dos } \\
\text { visitantes }\end{array}$ & 230 & 5 & 10 & 8,79 & 1,448 \\
\hline $\begin{array}{l}\text { RESP6: Visitantes se sentem livres para explorar (não há restrições de } \\
\text { acesso) }\end{array}$ & 230 & 0 & 10 & 8,37 & 2,096 \\
\hline $\begin{array}{l}\text { RESP7: A propriedade e suas áreas externas estão abertas em horários } \\
\text { convenientes }\end{array}$ & 230 & 1 & 10 & 8,85 & 1,554 \\
\hline RESP8: Funcionários estão semore disnoníveis auando necessário & 230 & 3 & 10 & 8.53 & 1.591 \\
\hline $\begin{array}{l}\text { TANG1: A propriedade se mostra em bom estado de manutenção e } \\
\text { restauração }\end{array}$ & 230 & 3 & 10 & 9,37 & 1,031 \\
\hline $\begin{array}{l}\text { TANG2: A limpeza geral e a manutenção da propriedade e suas áreas } \\
\text { externas são satisfatórias }\end{array}$ & 230 & 5 & 10 & 9,49 & 0,895 \\
\hline TANG3: Placas indicam adequadamente locais a serem visitados & 230 & 0 & 10 & 8.55 & 1.789 \\
\hline $\begin{array}{l}\text { TANG4: A propriedade oferece várias coisas interessantes a serem } \\
\text { exploradas }\end{array}$ & 230 & 5 & 10 & 9,50 & 0,919 \\
\hline $\begin{array}{l}\text { COM1: Folhetos escritos fornecem informações suficientes sobre suas } \\
\text { exposições }\end{array}$ & 230 & 1 & 10 & 8,10 & 1,940 \\
\hline $\begin{array}{l}\text { COM2: A informação acerca da propriedade e suas áreas externas é } \\
\text { detalhada de forma adequada }\end{array}$ & 230 & 2 & 10 & 8,20 & 1,683 \\
\hline $\begin{array}{l}\text { COM3: Visitantes são bem informados sobre atrações e exposições } \\
\text { disponiveis }\end{array}$ & 230 & 0 & 10 & 7,73 & 2,118 \\
\hline COM4: Folhetos escritos em línquas estranqeiras estão disponíveis & 230 & 0 & 10 & 8,11 & 2,228 \\
\hline CONS1: O restaurante oferece uma arande variedade de comidas e bebidas & 230 & 0 & 10 & 7,26 & 2,317 \\
\hline CONS2: A loia oferece uma arande variedade de mercadorias & 230 & 0 & 10 & 6.38 & 2.734 \\
\hline CONS3: Funcionários do restaurante oferecem um servico eficiente & 230 & 0 & 10 & 7.63 & 2.114 \\
\hline $\begin{array}{l}\text { EMP1: A propriedade considera as necessidades dos visitantes menos } \\
\text { capazes }\end{array}$ & 230 & 0 & 10 & 7,76 & 2,192 \\
\hline EMP2: Existem instalações voltadas para o público infantil & 230 & 0 & 10 & 6,10 & 2,921 \\
\hline $\begin{array}{l}\text { VALSOC1: Participar dessa experiência me permitiu criar uma boa } \\
\text { impressão }\end{array}$ & 230 & 0 & 10 & 9,31 & 1,449 \\
\hline $\begin{array}{l}\text { VALSOC2: Participar dessa experiência me permitiu impressionar outras } \\
\text { pessoas }\end{array}$ & 230 & 0 & 10 & 8,14 & 2,467 \\
\hline $\begin{array}{l}\text { VALSOC3: Participar dessa experiência me permitiu me sentir mais } \\
\text { socialmente aceito }\end{array}$ & 230 & 0 & 10 & 6,59 & 3,181 \\
\hline SAT1: Estou satisfeito com a minha decisão de barticipar dessa experiência & 230 & 4 & 10 & 9.43 & 1.090 \\
\hline SAT2: Minha decisão de participar dessa experiência foi sábia & 230 & 4 & 10 & 9,33 & 1,206 \\
\hline SAT3: Foi uma boa experiência & 230 & 5 & 10 & 9,54 & 0,859 \\
\hline
\end{tabular}

Fonte: Saída do SPSS. 


\subsection{Análise Fatorial Exploratória}

Para investigar as dimensões subjacentes da qualidade percebida pelos visitantes de Inhotim, procedeu-se a Análise Fatorial Exploratória (AFE) com os construtos adaptados do HISTOQUAL presentes no questionário, quais sejam: tangíveis, responsividade, comunicação, consumíveis e empatia.

Utilizou-se o software SPSS, versão 20.0, para a análise dos dados. Como preconizado por Hair et. Al. (2005), a extração Componentes Principais e rotação foi a Varimax.

Segundo os autores, o primeiro critério de adequação do uso da AFE é a inspeção do valor do $\mathrm{KMO}$, quanto mais próximo de 1, melhor. Além disso, o teste de Esfericidade de Bartlett deve ser significante $($ sig < 0,05$)$. Os resultados estão dentro do esperado, conforme tabela 4, KMO foi de 0,829 e o sig do teste de Bartlett foi igual a zero.
Tabela 4 - KMO e Teste de Esfericidade de Bartlett

\begin{tabular}{|c|c|c|}
\hline \multicolumn{2}{|c|}{$\begin{array}{l}\text { Kaiser-Meyer-Olkin Measure } \\
\text { of Sampling Adequacy. }\end{array}$} &, 829 \\
\hline \multirow[t]{3}{*}{ Bartlett's 92esto f Sphericity } & $\begin{array}{c}\text { Approx. } \\
\text { Chi- } \\
\text { Square }\end{array}$ & $\begin{array}{c}1261,18 \\
8\end{array}$ \\
\hline & df & 105 \\
\hline & Sig. & ,000 \\
\hline
\end{tabular}

Fonte: Saída do SPSS

Em seguida, cabe analisar a comunalidade dos indicadores. Para Hair et al. (2005). A comunalidade mínima do indicador deve ser 0,50. Assim, RESP4, RESP6, RESP7, COM4, EMP1 e EMP2 tiveram que ser retirados da análise, por não atingirem tal parâmetro.

Tabela 5 - Matriz de Componentes.

\begin{tabular}{|c|c|c|c|c|}
\hline \multirow[t]{2}{*}{ Indicadores } & \multicolumn{4}{|c|}{ Component } \\
\hline & 1 & 2 & 3 & 4 \\
\hline RESP 1...funcionários são sempre corteses e dispostos a ajudar no que for necessário. & ,742 & & & \\
\hline RESP 2....funcionários estão dispostos a passar o tempo com os visitantes. & ,714 & & & \\
\hline RESP 3...visitantes se sentem bem vindos. & 600 & & & \\
\hline RESP 5...funcionários são bem informados para responder às dúvidas dos visitantes. & 693 & & & \\
\hline RESP 8...funcionários estão sempre disponíveis quando necessário. & ,733 & & & \\
\hline TANG 1...a propriedade se mostra em bom estado de manutenção e restauração. & & & 870 & \\
\hline TANG 2...a limpeza geral e a manutenção da propriedade e suas áreas externas são satisfatórias. & & & 859 & \\
\hline TANG 3...placas indicam adequadamente locais a serem visitados. & & ,706 & & \\
\hline TANG 4...a propriedade oferece várias coisas interessantes a serem exploradas. & & & ,417 & \\
\hline COM 1...folhetos escritos fornecem informacões suficientes sobre suas exposiç̃es. & & 827 & & \\
\hline COM 2 ...a informação acerca da propriedade e suas áreas externas é detalhada de forma adequada. & & 813 & & \\
\hline COM 3...visitantes são bem informados sobre atrações e exposições disponíveis. & & ,752 & & \\
\hline CONS $1 \ldots$... restaurante oferece uma grande variedade de comidas e bebidas. & & & & 838 \\
\hline CONS 2.... loja oferece uma grande variedade de mercadorias. & & & & 619 \\
\hline CONS 3...funcionários do restaurante oferecem um serviço eficiente. & & & & ,765 \\
\hline
\end{tabular}

Fonte: Saída SPSS

Notas: Extraction Method: Principal Component Analysis.

Rotation Method: Varimax with Kaiser Normalization.

A matriz rotacionada das cargas fatoriais dos indicadores está na tabela 5 . Ressalta-se que TANG 3 (placas indicam adequadamente locais a serem visitados) agregou como item da dimensão comunicação, o que faz sentido. Placas foram percebidas pelos visitantes como indicador de comunicação, semelhante a folhetos. Nas análises subsequentes, TANG3 será avaliado como indicador do construto comunicação, respeitando 0 que fora aqui encontrado. 
Portanto, o modelo a ser testado contará com 4 dimensões de qualidade percebida, que, juntas, explicam $62,7 \%$ de variância dos dados, segundo resultados da AFE. A seguir, o modelo (FIG 1) será testado no SmartPLS.

Figura 4 - Modelo AI

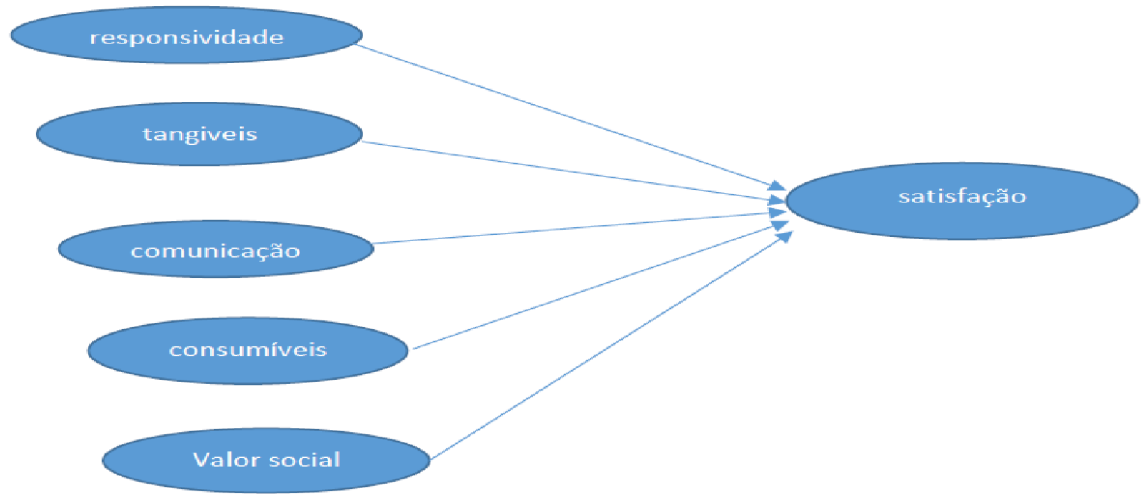

Fonte: Elaborado pelos autores (2017)

\subsection{Modelo de Mensuração}

Para testar o modelo proposto pela pesquisa optou-se pelo uso dos softwares IBM SPSS Statistics e Smart PLS 3.2.4. O modelo de mensuração foi composto pelas medidas de Confiabilidade (simples e composta), pela Validade Convergente (variância média extraída e cargas externas) e pela Validade Discriminante (cargas cruzadas, Fornell-Larcker e Heterotrait-Monotrait Ratio).

\subsection{Confiabilidade}

A confiabilidade simples do modelo é medido utilizando os valores do Alpha de Cronbach e a confiabilidade composta é medida usando os valores da confiabilidade composta.

Tabela 6 - Confiabilidade Simples e Composta.

\begin{tabular}{l|c|c}
\hline & $\begin{array}{c}\text { Confiabilidade } \\
\text { simples }\end{array}$ & $\begin{array}{c}\text { Confiabilidade } \\
\text { composta }\end{array}$ \\
\hline Comunicacão & $\begin{array}{c}\text { Alpha de } \\
\text { Cronbach }>\mathbf{0 , 7 0}\end{array}$ & $\begin{array}{c}\text { Confiabilidade } \\
\text { composta }>\mathbf{0 , 7 0}\end{array}$ \\
\hline Consumíveis & 0,826 & 0,884 \\
\hline Responsivida & 0,791 & 0,801 \\
\hline Satisfação & 0,811 & 0,853 \\
\hline Tanqíveis & 0,729 & 0,888 \\
\hline Valor social & 0,703 & 0,828 \\
\hline
\end{tabular}

Fonte: Saída do Software SmartPLS.

Tanto o Alpha de Cronbach quanto a confiabilidade composta possuem os mesmos parâmetros, valores inferiores a 0,60 são inaceitáveis, entre 0,60 e 0,70 são aceitáveis em pesquisas exploratórias, entre 0,70 e 0,90 são os valores ideais, ou seja, satisfatórios e valores acima de 0,90 são indesejáveis (HAIR; HULT; RINGLE; SARSTEDT, 2014). Todos os valores do Alpha de Cronbach e confiabilidade composta são considerados ideais com exceção do Alpha de Cronbach do construto Consumíveis que possui valor de 0,653. Porém ainda é um valor aceitável para pesquisa exploratória.

\subsection{Validade Convergente}

A validade convergente do estudo foi analisada usando como base os valores da variância média extraída (AVE) e as cargas externas. A AVE possui valores satisfatórios que sejam iguais ou superiores a 0,50 e valores de cargas externas superiores a 0,70 (HAIR et al. 2014). Conforme a tabela 7, todos os construtos possuem valores de AVE satisfatórios.

Tabela 7 - Variância Média Extraída (AVE)

\begin{tabular}{l|l}
\hline \multicolumn{2}{c}{ AVE $\geq 0,50$} \\
\hline Comunicacão & 0.657 \\
\hline Consumíveis & 0,594 \\
\hline Responsividade & 0.539 \\
\hline Satisfacão & 0.726 \\
\hline Tanqíveis & 0.618 \\
\hline Valor Social & 0.625 \\
\hline
\end{tabular}

Fonte: Saída do Software SmartPLS.

A tabela 8 apresenta os valores das cargas externas para cada item dos construtos, e como pode ser visto, os itens CONS2, RESP2 e RESP5 apresentaram valores de carga externa insatisfatório, porém como tanto o construto CONS quanto 0 
construto RESP possuem valores de AVE adequados optou-se pela manutenção dos mesmos.

Além disso, nos casos em que o item apresenta valor de carga externa entre 0,40 e 0,70 Hair et al. (2014) indicam que devem ser retirados caso a exclusão melhorem a AVE e a confiabilidade composta, mas como a AVE e a confiabilidade composta apresentam valores satisfatórios e a diferença entre os valores adequados e os apresentados pelos itens RESP2 e RESP5 é baixo, optou-se pela manutenção do item para uma maior amplitude do estudo.

Tabela 8 - Cargas Externas (Outer Loadings).

\begin{tabular}{|c|c|c|c|c|c|c|}
\hline \multicolumn{7}{|c|}{ Caraas externas $>0.70$} \\
\hline & Comunicacão & Consumíveis & Responsividade & Satisfacão & Tanaíveis & Valor Social \\
\hline COM1 & 0.810 & & & & & \\
\hline COM2 & 0,843 & & & & & \\
\hline COM3 & 0,803 & & & & & \\
\hline CONS1 & & 0.939 & & & & \\
\hline CONS2 & & 0,427 & & & & \\
\hline CONS3 & & 0,847 & & & & \\
\hline RESP1 & & & 0,827 & & & \\
\hline RESP2 & & & 0,644 & & & \\
\hline RESP3 & & & 0,789 & & & \\
\hline RESP5 & & & 0.658 & & & \\
\hline RESP8 & & & 0,735 & & & \\
\hline SAT1 & & & & 0,870 & & \\
\hline SAT2 & & & & 0.854 & & \\
\hline SAT3 & & & & 0,832 & & \\
\hline TANG1 & & & & & 0.711 & \\
\hline TANG2 & & & & & 0.803 & \\
\hline TANG3 & 0,784 & & & & & \\
\hline TANG4 & & & & & 0.839 & \\
\hline VALSOC1 & & & & & & 0.786 \\
\hline VALSOC2 & & & & & & 0,826 \\
\hline VALSOC3 & & & & & & 0.757 \\
\hline
\end{tabular}

Fonte: Saída do Software SmartPLS.

\subsection{Validade Discriminante}

A análise da validade discriminante foi realizada através de três métodos, as cargas cruzadas onde a carga de um item sobre o construto do mesmo deve ser maior que todas as desse item sobre os demais construtos; o critério Fornell-Larcker segundo o qual cada construto deve compartilhar mais variância com seus itens do que com outros construtos e HTMT onde esses valores entre as relações dos construtos devem ser menores que 0,90 (HAIR et al.,2014).

Como pode ser visto nas tabelas 9,10 e 11 todos os critérios utilizados para a análise da validade discriminante foram satisfeitos, à exceção da carga cruzada do item TANG3 que migrou e foi analisada junto ao construto Comunicação. 
O Que Faz o Visitante do Inhotim Tão Satisfeito?

Marlusa de Sevilha Gosling, Danielle Carolina de Queiroz, Luciana de Rio Meints \& Juliana Maria Magalhães Christino

Tabela 9 - Cargas Cruzadas (Cross Loadings).

\begin{tabular}{|c|c|c|c|c|c|c|}
\hline \multicolumn{7}{|c|}{ Caraas externas $>0.70$} \\
\hline & Comunicacão & Consumíveis & Responsividade & Satisfacão & Tanaíveis & Valor Social \\
\hline COM1 & 0.810 & 0.177 & 0.321 & 0.154 & 0.364 & 0.277 \\
\hline COM2 & 0.843 & 0.316 & 0.393 & 0.187 & 0.398 & 0.301 \\
\hline COM3 & 0.803 & 0.237 & 0.362 & 0.204 & 0.345 & 0.276 \\
\hline CONS1 & 0.304 & 0.939 & 0.311 & 0.240 & 0.284 & 0.254 \\
\hline CONS2 & 0.039 & 0.427 & 0.140 & 0.059 & 0.117 & 0.025 \\
\hline CONS3 & 0.265 & 0.847 & 0.393 & 0.155 & 0.323 & 0.188 \\
\hline RESP1 & 0.320 & 0.409 & 0.827 & 0.334 & 0.417 & 0.307 \\
\hline RESP2 & 0.307 & 0.195 & 0.644 & 0.212 & 0.228 & 0.201 \\
\hline RESP3 & 0.356 & 0.252 & 0.789 & 0.454 & 0.521 & 0.384 \\
\hline RESP5 & 0.322 & 0.207 & 0.658 & 0.219 & 0.324 & 0.260 \\
\hline RESP8 & 0.292 & 0.299 & 0.735 & 0.302 & 0.377 & 0.245 \\
\hline SAT1 & 0.270 & 0.185 & 0.337 & 0.870 & 0.459 & 0.362 \\
\hline SAT2 & 0.149 & 0.154 & 0.395 & 0.854 & 0.457 & 0.446 \\
\hline SAT3 & 0.187 & 0.232 & 0.390 & 0.832 & 0.481 & 0.395 \\
\hline TANG1 & 0.347 & 0.248 & 0.316 & 0.205 & 0.711 & 0.366 \\
\hline TANG2 & 0.338 & 0.270 & 0.439 & 0.379 & 0.803 & 0.352 \\
\hline TANG3 & 0.784 & 0.243 & 0.323 & 0.202 & 0.403 & 0.271 \\
\hline TANG4 & 0.411 & 0.265 & 0.467 & 0.567 & 0.839 & 0.331 \\
\hline VALSOC1 & 0.293 & 0.237 & 0.357 & 0.423 & 0.436 & 0.786 \\
\hline VALSOC2 & 0.191 & 0.182 & 0.288 & 0.378 & 0.304 & 0.826 \\
\hline VALSOC3 & 0.356 & 0.133 & 0.285 & 0.302 & 0.246 & 0.757 \\
\hline
\end{tabular}

Fonte: Saída do Software SmartPLS.

Tabela 10 - Fornell-Larcker.

\begin{tabular}{l|l|l|l|l|l|l}
\hline & Comunicacão & Consumíveis & Responsividade & Satisfacão & Tanaíveis & Valor Social \\
\hline Comunicacão & $\mathbf{0 . 8 1 0}$ & & & & & \\
\hline Consumíveis & 0.304 & $\mathbf{0 . 7 7 1}$ & & & & \\
\hline Responsivildade & 0.433 & 0.376 & $\mathbf{0 . 7 3 4}$ & & & \\
\hline Satisfacão & 0.234 & 0.223 & 0.441 & $\mathbf{0 . 8 5 2}$ & & \\
\hline Tanaíveis & 0.467 & 0.328 & 0.536 & 0.548 & $\mathbf{0 . 7 8 6}$ & \\
\hline Valor Social & 0.348 & 0.240 & 0.396 & 0.473 & 0.428 & $\mathbf{0 . 7 9 0}$ \\
\hline
\end{tabular}

Fonte: Saída do Software SmartPLS.

Tabela 11 - Heterotrait-Monotrait Ratio (HTMT).

\begin{tabular}{l|l|l|l|l|l|l}
\hline & Comunicacão & Consumíveis & Responsividade & Satisfacão & Tanaíveis & Valor Social \\
\hline Comunicacão & & & & & & \\
\hline Consumíveis & 0.361 & & & & & \\
\hline Responsivldade & 0.532 & 0.498 & & & & \\
\hline Satisfacão & 0.286 & 0.270 & 0.511 & & & \\
\hline Tanaíveis & 0.583 & 0.443 & 0.631 & 0.617 & & \\
\hline Valor Social & 0.463 & 0.305 & 0.504 & 0.611 & 0.593 & \\
\hline
\end{tabular}

Fonte: Saída do Software SmartPLS. 


\subsection{Modelo Estrutural}

Para a análise do teste do modelo estrutural proposto pelo estudo, foram usados os coeficientes de caminho, os coeficientes de determinação e o SRMR. O modelo foi testado pelo software SmartPLS e o Bootstrapping foi analisado com uma amostra de 1000.

Figura 4 - Modelo de Estrutural.

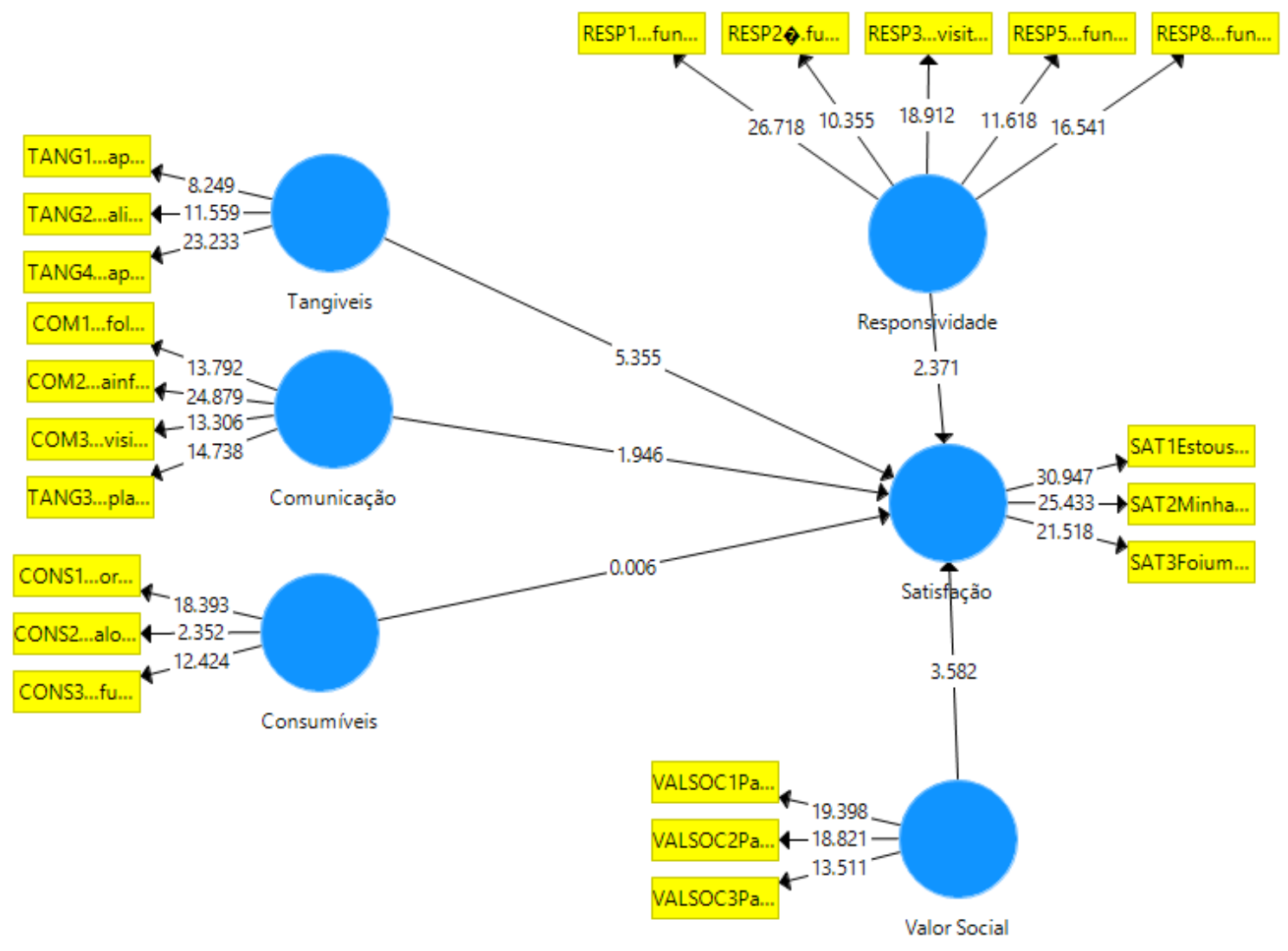

Fonte: Saída do Software SmartPLS.

\subsection{Coeficiente de Caminho}

Para identificar a significância dos coeficientes, utilizamos como parâmetro o Teste T. O valor do teste $\mathrm{T}$ deve ser superior a 2,57 para uma significância a $1 \%, 1,96$ para a significância a $5 \%$ e 1,57 para a significância a $10 \%$ e valores inferiores a 1,57 são considerados não significantes (HAIR et al., 2014).
Conforme a tabela 12, o coeficiente de caminho, Consumíveis $\rightarrow$ Satisfação não é significante; 0 coeficiente de caminho, Comunicação $\rightarrow$ Satisfação é significante a $10 \%$; o coeficiente de caminho, Responsividade $\rightarrow$ Satisfação é significante a $5 \%$; e os coeficientes de caminho, Tangíveis $\rightarrow$ Satisfação e Valor Social $\rightarrow$ Satisfação são significantes a $1 \%$.

Tabela 12 - Coeficientes de Caminho.

\begin{tabular}{l|l|l|l}
\hline \multicolumn{1}{c|}{ Hioótese } & Estatística T & P Valor & Sianificância \\
\hline Comunicacão=>Satisfacão & 1.946 & 0.052 & $10 \%$ \\
\hline Consumíveis=>Satisfacão & 0.006 & 0.995 & Não sianificante \\
\hline Responsividade=>Satisfação & 2,371 & 0,018 & $5 \%$ \\
\hline Tanaíveis=>Satisfacão & 5.355 & 0.000 & $1 \%$ \\
\hline Valor social=>Satisfacão & 3.582 & 0.000 & $1 \%$ \\
\hline
\end{tabular}

Fonte: Saída do Software SmartPLS. 


\subsection{Coeficiente de Determinação $\left(R^{2}\right)$}

Os coeficientes de determinação $\left(R^{2}\right)$ variam entre 0 e 1 e quanto mais próximos de 1 maior é a capacidade de previsão. Os coeficientes de determinação devem ser avaliados pelos parâmetros de valores de $0,19,0,33$ e 0,67 , sendo respectivamente, fracos, moderados e substanciais (HENSELER et al., 2009; HAIR et al., 2014). Conforme os dados da tabela 13, os coeficientes de determinação do construto satisfação são considerados moderados.

Tabela 13 - Coeficiente de Determinação.

\begin{tabular}{l|r|r}
\hline Construto & $\mathbf{R}^{2}$ & $\mathbf{R}^{2}$ aiustado \\
\hline Satisfacão & 0.3 & 0.381 \\
\hline
\end{tabular}

Fonte: Saída do Software Smart PLS

\subsection{Standardized Root Mean Square Residual (SRMR)}

O Standardized Root Mean Square Residual (SRMR) é a diferença entre a correlação observada e prevista. O valor de SRMR considerado bom é de até 0,10. (HU; BENTLER, 1998).

Tabela 14 - SRMR.

\begin{tabular}{c}
\hline SRMR \\
\hline 0.077 \\
\hline
\end{tabular}

Fonte: Saída do Software Smart PLS

Conforme a tabela 14, o valor do SRMR apresentado pelo modelo é adequado.

\section{CONCLUSÃO}

Esse trabalho analisou quais são os construtos que impactam na satisfação de clientes do museu Inhotim localizado em Brumadinho-MG. A escala HISTOQUAL (com os construtos Responsividade, Tangíveis, Comunicação, Consumiveis e Empatia) foi adaptada e o construto Valor Social foi acrescentado.

A Análise Fatorial Exploratória mostrou que 0 construto Empatia não deveria ser considerado no teste do modelo, além da necessidade de retirada de alguns outros itens, que tiveram baixa comunalidade.

0 modelo final apresentou um bom ajuste em termos de confiabilidade simples e composta e validade convergente e discriminante. Em termos das relações (modelo estrutural), somente o construto consumíveis não foi estatisticamente significante para prever a satisfação dos visitantes pesquisados.
Tangíveis, responsividade, comunicação e valor social, juntos explicam cerca de $38 \%$ da satisfação dos visitantes. Portanto, existem variáveis que não foram consideradas que devem ser pesquisadas em estudos futuros, para prever e explicar a satisfação das pessoas que visitam Inhotim.

Também se faz relevante enfatizar que os resultados aqui mostrados não devem ser generalizados, já que a amostra não foi aleatória. Adicionalmente, pesquisas futuras podem avaliar esse construto Valor Social em outros museus. Por fim, é interessante avaliar futuramente se a cocriação seria um fator mediador ou moderador em relação à Satisfação.

\section{REFERÊNCIAS BIBLIOGRÁFICAS}

ALI, F.; RYU, K.; HUSSAIN, K. Influence of Experiences on Memories, Satisfaction and Behavioral Intentions: a Study of Creative Tourism. Journal of Travel \& Tourism Marketing, 2015.

BABAKUS, E., BOLLER, G.W. An empirical assessment of the SERVQUAL scale. Journal of Business Research, v.24, n.3, p.253-268, 1992.

BECKER-OLSEN, K.L.; CUDMORE, B.A.; HILL, R.P. The impact of perceived corporate social responsibility on consumer behavior. Journal of Business Research, v.59, n.1, p.46-53, 2006.

BELK, R. W. Possessions and the Extended Self. Journal of Consumer Research, v. 15, n. 2, p. 139-168, Set. 1988.

BELK, R. W. Extended Self in a Digital World. Journal of Consumer Research, v. 40, n. 3, p. 477-500, 2014.

BERMAN, J.Z.; SMALL, D. Judgments of virtue in consumer behavior. Advances in Consumer Research, v.42, p.412, 2014.

BOORSMA M. A Strategic Logic for Arts Marketing. International Journal of Cultural Policy v. 12, n. 1,. p. 73-92, 2006

BROWN, T.J.; CHURCHILL Jr., G.A.; PETER, J.P. Improving the measurement of service quality. Journal of Retailing, v.69, n.1, p.127-139, 1993.

CHEN, C.F.; CHEN, F.S. Experienced quality, perceived value, satisfaction and behavioral intentions for heritage tourists. Tourism Management, v.31, n.1, p. 29-35, 2010.

CHEN, N.; DWYER, L.; FIRTH, T. Effect of dimensions of place attachment on residents' word-of-mouth behaviour. v. $16, \mathrm{n}^{0} \quad 5,826-843$. Tourism Geographies, 2014.

COHEN, S.; PRAVAG, G.; MOITAL, M. (2013): Consumer behaviour in tourism: Concepts, influences and opportunities

DE MOOIJ, M.; HOFSTEDE, G. Convergence and divergence in consumer behavior: implications for international retailing. Journal of Retailing, v.78, n.1, p.61-69, 2002.

DE ROJAS, C.; CAMARERO, C. Visitors' experience, mood 
and satisfaction in a heritage context: evidence from an interpretation center. Tourism Management, v.29, n.3, p.525-537, 2008.

FOREMAN-WERNET, L.; DERVIN, B. Cultural experience in context: sense-making the arts. The Journal of Arts Management, Law, and Society, v. 41, n.1, p.1-37, 2011.

FROCHOT, I.; HUGHES, H. HISTOQUAL: the development of a historic houses assessment scale. Tourism Management, v. 21, n.2, p. 157-167, 2000.

HAIR ET AL. Fundamentos de Métodos de Pesquisa em Administração. Porto Alegre: Bookman, 2005

HAIR, J.; HULT, G. T. M.; RINGLE, C. M.; SARSTEDT, M. A Primer on Partial Least Squares Structural Equation Modeling (PLS-SEM). Los Angeles: Sage Publications, 2014.

HENSELER, J.; RINGLE, C. M. \& SINKOVICS, R. R. The use of partial least squares path modeling in international marketing. Advances in International Marketing (AIM), v. 20, p. 277-320, 2009.

HU, L. T. \& BENTLER, P. M. Fit indices in covariance structure modeling: sensitivity to underparameterized model misspecification. Psychological Methods, v. 3 , n. 4, p. 424-453, 1998.

JAFARI, A.; TAHERI, B.; VOM LEHN, D. Cultural consumption, interactive sociality, and the museum. Journal of Marketing Management, v. 29, n.15-16, p. 1729-1752, 2013.

KISIDA, B.; GREENE, J.P.; BOWEN, D.H. Creating cultural consumers: the dynamics of cultural capital acquisition. Sociology of Education, v.87, n.4, p.281295, 2014.

$\mathrm{KOVACH}, \mathrm{D} . \mathrm{S}$. Developing the museum experience: retailing in American museums 1945-91. Museum History Journal, v.7, n.1, p.103-121, 2014.

LAMBERT, T. S.; BOUKAS, N.; YERALI, M. C. Museums and cultural sustainability: stakeholders, forces, and cultural policies, International Journal of Cultural Policy, v. 20 n. 5, p. 566-587, 2014.

LEE, H.; LEE, Y.; YOO, D. The determinants of perceived service quality and its relationship with satisfaction. Journal of Services Marketing, v. 14, n.3, p.217-231, 2000.

LEE, Y.L.; HING, N. Measuring quality in restaurant operations: an application of the SERVQUAL instrument. International Journal of Hospitality Management, v.14, n.3-4, p.293-310, 1995.

LEE, Y. K.; LEE, C. K.; LEE, S. K.; BABIN, B. J. Festivalscapes and patrons' emotions, satisfaction and loyalty. Journal of Business Research, v. 61, n.1, p. 56-64, 2008. LOPES, E.L.; SILVA, D. Modelos integrativos do comportamento do consumidor: uma revisão teórica. Revista Brasileira de Marketing, v.10, n.3, p.3-23, 2011.

MALHOTRA, Naresh K. Pesquisa de marketing: uma orientação aplicada. 6. ed. Porto Alegre: Bookman, 2010. 735 p.

MARCHETTI, R.; PRADO, P.H.M. Um tour pelas medidas de satisfação do consumidor. Revista de Administração de Empresas, v.41, n.4, p.56-67, 2001.
MCKERCHER, B.; DENIZCI-GUILLET, B.; NG, E. Rethinking loyalty. Annals of Tourism Research, v. 39, n. 2, p. 708-734, 2012.

MOWEN, J.C. Beyond consumer decision making. Journal of Consumer Marketing, v. 5, n.1., p.15-25, 1988.

NEWMAN, A.; McLEAN, F. Presumption, policy and practice: the use of museums and galleries as agents of social inclusion in Great Britain. International Journal of Cultural Policy, v.10, n.2, p.167-181, 2004.

NEWMAN, K. Interrogating SERVQUAL: a critical assessment of service quality measurement in a high street retail bank. International Journal of Bank Marketing, v.19, n.3, p.126-139, 2001.

OLIVER, R. L. Satisfaction: a behavioral perspective on the consumer. New York: McGraw Hill, 1997.

PACKER, J. Beyond learning: exploring visitors' perceptions of the value and benefits of museum experiences. Curator, v.51, n.1, p.33-54, 2008.

PARASURAMAN, A.; ZEITHAML, V.A.; BERRY, L.E. A conceptual model of service quality and its implications for future research. Journal of Marketing, v.49, n.4, p.41-50, 1985.

PARASURAMAN, A.; ZEITHAML, V.A.; BERRY, L.E. More on improving service quality measurement. Journal of Retailing, v.69, n.1, p.140-147, 1993.

PARASURAMAN, A.; ZEITHAML, V.A.; BERRY, L.E. Refinement and reassessment of the SERVQUAL scale. Journal of Retailing, v.67, n.4, p.420-450, 1991.

PARASURAMAN, A.; ZEITHAML, V.A.; BERRY, L.E. SERVQUAL: a multiple-item scale for measuring consumer perceptions of service quality. Journal of Retailing, v.64, n.1, p.12-40, 1988.

PINTO, M. de R.; LARA, J.E. O que se publica sobre comportamento do consumidor no Brasil, afinal? Revista de Administração UFSM, v.1, n.1, p.85-100, 2008.

RODRIGUES, J.M.S. Gestão da satisfação e fidelidade de consumidores: um estudo dos fatores que afetam a satisfação e qualidade no mercado de turismo. 2003. 83f. Dissertação (Mestrado em Ciências em Engenharia de Produção) - Centro de Tecnologia, Universidade Federal do Rio Grande do Norte, Natal, 2003.

ROWLEY, J. Measuring total customer experience in museums. International Journal of Contemporary Hospitality Management, v.11, n.6, p. 303-308, 1999.

SALEH, F.; RYAN, C. Analysing service quality in the hospitality industry using the SERVQUAL model. The Service Industries Journal, v.11, n.3, p. 324-345, 1991.

SCOTT, C. Museums and impact. Curator, v.46, n.3, p.293310, 2003.

SETH, N.; DESHMUKH, S.G.; VRAT, P. Service quality models: a review. The International Journal of Quality \& Reliability Management, v.22, n.9, p. 913-949, 2005.

STRAUGHAN, R.D.; ROBERTS, J.A. Environmental segmentation alternatives: a look at green consumer behavior in the new millennium. Journal of Consumer Marketing, v.16, n.6, p.558-575, 2006.

HORNER, S.; SWARBROOKE, S. Consumer behaviour in 
tourism. 3 edição, Nova lorque, NY, 2016.

TAN, K.C.; KEK, S. W. Service quality in higher education using an enhanced SERVQUAL approach. Quality in Higher Education, v.10, n.1, p. 17-24, 2004.

TRANT, J.; WYMAN, B. Investigating social tagging and folksonomy in art museums with steve.museum. Disponível em: $<$ http://www.archimuse.com/research/www2006tagging-steve.pdf> Acesso em: 21 out. 2016.
VAN IWAARDEN, J.; VAN DER WIELE, T.; BALL, L.; MILLEN, R. Applying SERVQUAL to web sites: an exploratory study. International Journal of Quality and Reliability Management, v.20, n.8, p.919-935, 2003.

WISNIEWSKI, M. Using SERVQUAL to assess customer satisfaction with public sector services. Managing Service Quality: An International Journal, v.11, n.6, p.380-388, 2001.

Processo Editorial / Editorial Process

Editor Chefe/Editor-in-chief: PhD Thiago D. Pimentel (UFJF).

Recebido em 27 de Junho de 2017; aceito em 20 de Setembro de 2017; publicado online 31 de Outubro de 2017.

Received on June 27, 2017; accepted on September 20, 2017, published online on October 31, 2017.

Artigo original de revisão/ Original revisional article. Seção revisada por pares / Double bind review section. 